CARDIOVASCULAR MEDICINE

\title{
Determinants of persistent negative T waves and early versus late $T$ wave normalisation after acute myocardial infarction
}

\section{A Pierard, P Lancellotti}

Heart 2005;91:1008-1012. doi: 10.1136/hrt.2004.033936

See end of article for authors' affiliations .....................

Correspondence to: Professor Luc A Pierard Department of Cardiology, University Hospital of Liège, B-4000 Liege, Belgium; lpierard@chu. ulg.ac.be

Accepted 15 July 2004
Objective: To determine whether persistent versus early or delayed T wave normalisation of negative $T$ waves after acute myocardial infarction is determined by the myocardial state, the treatment strategy, or both.

Design: 127 consecutive patients with a first acute myocardial infarction and $\geqslant 2$ negative $T$ waves on the 24-36 hour ECG were studied. They underwent dobutamine stress echocardiography and coronary angiography during the first week. ECG was recorded at hospital discharge and at a mean (SD) of 4 (1) months.

Setting: University hospital.

Results: T wave normalisation was observed in 88 patients (early at discharge in 19 and delayed at four months in 69). Early $T$ wave normalisation was associated with sustained contractile reserve during dobutamine stress (13 of $19(68 \%))$, whereas delayed T wave normalisation was observed mainly in patients with an ischaemic response (49 of $69(71 \%))$. The persistence of negative T waves was associated with an ischaemic response (21 of $39(54 \%))$ or persistent akinesis (17 of $39(44 \%))$. Among patients with an ischaemic response to dobutamine, in-hospital elective angioplasty was an independent determinant of delayed T wave normalisation (39 of $49 v 4$ of 21 patients with persistent negative T waves at four months, $\mathrm{p}<0.0001$.

Conclusions: Early T wave normalisation is associated with dobutamine induced, sustained improvement indicating myocardial stunning. Delayed normalisation is observed mainly in patients with ischaemic myocardium who have undergone revascularisation. Persistent negative T waves correspond to either extensive necrosis or non-revascularised, jeopardised myocardium.
$\mathrm{T}$ he clinical significance of negative $\mathrm{T}$ waves after acute myocardial infarction is controversial. Negative $T$ waves early after thrombolysis are associated with patency of the infarct related artery, mild to moderate residual stenosis, and preserved left ventricular function ${ }^{1-3}$ and are an independent predictor of one month survival. ${ }^{4}$ In contrast, negative $\mathrm{T}$ waves were a predictor of death in long term studies analysing patients who survived three to four months after acute myocardial infarction. ${ }^{56}$ These contradictory observations probably relate to differing characteristics of persistent negative $\mathrm{T}$ waves as opposed to reversible negative $\mathrm{T}$ waves that normalise over time. Spontaneous normalisation of negative $\mathrm{T}$ waves is a marker of myocardial viability $^{78}$ and predicts recovery of regional dysfunction. ${ }^{9}{ }^{10}$ Functional recovery is greater in the presence of early $\mathrm{T}$ wave normalisation. ${ }^{11}$ Persistent negative T waves have been found to be associated with transmural necrosis. ${ }^{12}$ Accordingly, we hypothesised that persistent versus early or delayed normalisation of negative $\mathrm{T}$ waves after a first acute myocardial infarction are determined by the myocardial state, the treatment strategy, or both.

\section{METHODS}

\section{Patient selection}

The study population consisted of 127 consecutive patients prospectively enrolled with the following inclusion criteria: diagnosis of acute myocardial infarction (typical chest pain $\geqslant 30$ minutes with acute ST segment elevation in $\geqslant 2$ leads and an increase in serum creatine kinase $(\mathrm{CK}) \geqslant 2$ times the upper limit); no history of previous acute myocardial infarction; lack of intraventricular conduction disturbance and no ECG sign of left ventricular hypertrophy; negative T waves in $\geqslant 2$ infarct related leads $24-36$ hours after the acute event; coronary angiography and rest and dobutamine stress echocardiography performed within the first week of hospitalisation; and no occurrence of any cardiac event (cardiac death, recurrent angina, myocardial infarction, episode of congestive heart failure) between inclusion and the four month ECG and echocardiogram. The protocol was approved by the human ethics committee of our university hospital and all patients gave informed consent.

\section{ECG analysis}

Twelve lead ECGs were recorded on hospital admission, on the second and third day, at hospital discharge (mean (SD) 13 (2) days, range 8-16 days) and at 4 (1) months after the acute event. $\mathrm{T}$ waves were considered negative when the negative amplitude was $\geqslant 0.1 \mathrm{mV}$. $\mathrm{T}$ wave normalisation corresponded to abnormal negative $\mathrm{T}$ waves becoming positive or isoelectric in $\geqslant 2$ infarct related leads either at hospital discharge (early) or on the four month ECG (delayed) ${ }^{4-6}$

\section{Dobutamine stress echocardiography}

$\beta$ Adrenergic blocking agents were withdrawn 48 hours before the study. Dobutamine was infused at incremental doses of $5-40 \mu \mathrm{g} / \mathrm{kg} / \mathrm{min}$ at three minute intervals. Atropine (0.25 $\mathrm{mg}$ to a maximum dose of $1 \mathrm{mg}$ ) was added if the target heart rate was not obtained. The infusion was stopped in the presence of classic end points. Echocardiographic images were acquired digitally at rest, at low dobutamine dose, at peak stress, and during recovery for side by side 
display in a quad screen format (Vingmed CFM 800 or General Electric System Five, Horten, Norway). Parasternal long and short axis, apical long axis, and four and two chamber views were analysed. For both rest and stress studies, the left ventricular wall was divided into 16 segments and scored on a four point scale, allowing calculation of a wall motion score index, where 1 indicates normal wall thickening; 2, hypokinesis; 3, akinesis; and 4, dyskinesis. Changes from dyskinesis to akinesis and from akinesis to dyskinesis were not considered to indicate viability and ischaemia. Four echocardiographic responses were identified: firstly, sustained improvement; secondly, biphasic response (initial improvement of contractility by $\geqslant 1$ score in the infarct area followed by subsequent worsening); thirdly, worsening in an adjacent area (new dyssynergy induced in $\geqslant 2$ segments adjacent to the infarcted zone with no change in the affected segments); and fourthly, akinesis without change throughout the dobutamine test. Functional recovery was defined on the four month resting echocardiogram as improvement in wall thickening in at least two contiguous dyssynergic segments.

\section{Angiography}

All patients underwent quantitative coronary angiography and left ventriculography within one week after the dobutamine test. Coronary stenoses were measured quantitatively with the use of the CMS system (MEDIS, Leiden, the Netherlands). Left ventricular end diastolic and end systolic volumes were determined by the area-length method and ejection fraction was calculated. An experienced cardiologist performed elective coronary angioplasty. ECG findings and the results of dobutamine stress echocardiography were not used in the decision process.

\section{Statistical analysis}

Values are expressed as mean (SD). Student's $t$ test was used to assess differences between mean values. Categorical variables were compared by $\chi^{2}$ test and Fisher's exact test when appropriate. To detect covariates associated with early and late $\mathrm{T}$ wave normalisation, a stepwise logistic regression procedure according to forward selection stepwise analysis was performed, including clinical, angiographic, and echocardiographic variables. Multivariate logistic regressions were performed on the variables found to be significant in the stepwise analysis with the quasi-Newton logistic regression model. Significance was defined as $\mathrm{p} \leqslant 0.05$.

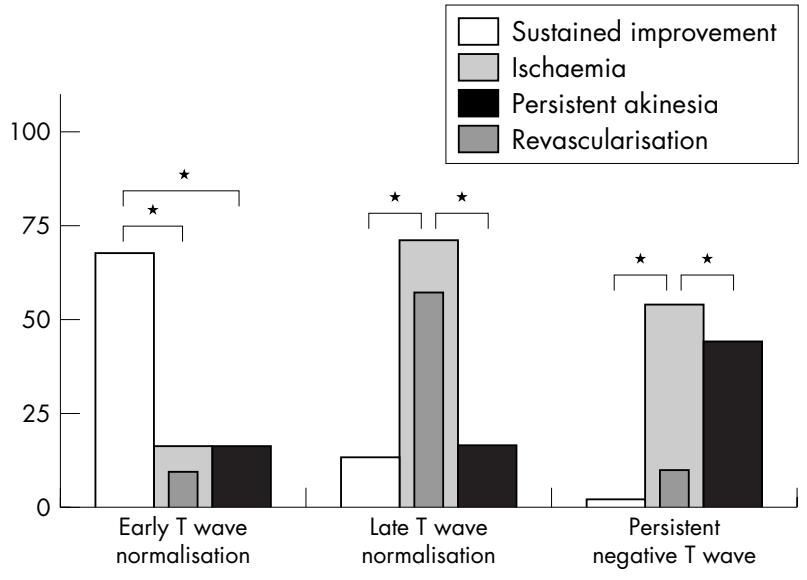

Figure 1 Bar graph showing the distribution of dobutamine echocardiographic responses in the three groups according to $T$ wave evolution. Superimposed grey bars represent percentage of revascularisation in patients exhibiting dobutamine induced ischaemia. ${ }^{*} \mathrm{p}<0.05$.

\section{RESULTS}

\section{ECG changes}

Thirty nine patients $(31 \%)$ had persistent negative T waves on the four month follow up ECG. T wave normalisation was observed early at hospital discharge in $19(15 \%)$ and late, between discharge and the four month follow up, in 69 (54\%) patients.

\section{Clinical and angiographic data}

There were no differences between the three groups in age, sex, thrombolytic treatment, and Q wave infarction (table 1). Patients with persistent negative T waves at four months had higher left ventricular volumes, had lower left ventricular ejection fractions, and were more likely to have multivessel disease. $\mathrm{T}$ wave normalisation before hospital discharge was associated with lower peak CK and CK-MB concentrations, lower left ventricular volumes, higher left ventricular ejection fraction, and a lower incidence of severe stenosis of the infarct related artery. Patients with delayed $\mathrm{T}$ wave normalisation underwent more elective angioplasty procedures of the infarct related artery and had more anterior acute myocardial infarctions.

Table 1 Comparison between patients with early, delayed, and no T wave normalisation

\begin{tabular}{lllll}
\hline & $\begin{array}{l}\text { Early T wave } \\
\text { normalisation } \\
(\mathbf{n = 1 9 )}\end{array}$ & $\begin{array}{l}\text { Delayed T wave } \\
\text { normalisation } \\
(\mathbf{n = 6 9 )}\end{array}$ & $\begin{array}{l}\text { Persistent negative } \\
\text { T waves } \\
\text { (n=39) }\end{array}$ & p Value \\
Data & $59(10)$ & $59(12)$ & $58(9)$ & NS \\
\hline Age (years) & $89 \%$ & $84 \%$ & $82 \%$ & NS \\
Men & 15 & 48 & 28 & NS \\
Thrombolytic treatment & $1343(524)$ & $1862(818)$ & $2045(908)$ & 0.009 \\
Peak CK (IU/I) & $132(48)$ & $186(65)$ & $204(68)$ & 0.0003 \\
Peak CK-MB (IU/I) & 7 & 43 & 13 & 0.007 \\
Anterior infarction & 15 & 65 & 26 & NS \\
Q wave infarction & $1.30(0.19)$ & $1.39(0.22)$ & $1.54(0.35)$ & 0.003 \\
Score index at baseline & $63(8)$ & $59(11)$ & $50(14)$ & $<0.0001$ \\
LVEF (\%) & $135(31)$ & $153(37)$ & $181(41)$ & 0.00034 \\
EDV (ml) & $50(19)$ & $68(32)$ & $89(49)$ & 0.00035 \\
ESV (ml) & 4 & 7 & 12 & 0.025 \\
Occluded infarct artery & $50(7)$ & $70(16)$ & $74(12)$ & $<0.0001$ \\
Residual stenosis (\%) & 4 & 49 & 31 & 0.0001 \\
$\geqslant 70 \%$ IRA stenosis & 6 & 18 & 21 & 0.013 \\
$\geqslant 2$ vessel disease & 6 & 53 & 18 & $<0.0001$ \\
Revascularisation & & & & \\
\hline
\end{tabular}

Values are mean (SD) or number.

CK, creatine kinase; EDV, end diastolic volume; ESV, end systolic volume; IRA, infarct related artery; LVEF, left ventricular ejection fraction; NS, not significant. 
Table 2 Relation between stress echocardiographic responses, T wave changes, and elective revascularisation

\begin{tabular}{clcc}
\hline & $\begin{array}{l}\text { Early T wave } \\
\text { normalisation } \\
(\mathbf{n = 1 9 )}\end{array}$ & $\begin{array}{l}\text { Late T wave } \\
\text { normalisation negative T } \\
(\mathbf{n}=69)\end{array}$ & $\begin{array}{c}\text { Persistent } \\
\text { wave }(\mathbf{n = 3 9 )}\end{array}$ \\
\hline Sustained improvement & 13 & 9 & 1 \\
Number revascularised & 2 & 6 & 1 \\
Biphasic response & 1 & 35 & 15 \\
Number revascularised & 1 & 25 & 3 \\
Ischaemia in adjacent area & 2 & 14 & 6 \\
Number revascularised & 1 & 14 & 1 \\
Akinesis without change & 3 & 11 & 17 \\
Number revascularised & 2 & 8 & 13 \\
\hline
\end{tabular}

\section{Dobutamine stress echocardiographic data}

No complications occurred as a result of dobutamine stress echocardiography. The score index at baseline was higher in patients with persistent negative T waves. Table 2 shows the distribution of dobutamine stress echocardiography responses in the three groups and the number of patients who underwent elective revascularisation.

Most patients ( 13 of $19(68 \%)$ ) with predischarge restored $\mathrm{T}$ waves exhibited sustained improvement. An ischaemic response was often observed in patients with delayed $\mathrm{T}$ wave normalisation (49 of $69(71 \%)$ ): a biphasic response was seen in 35 and ischaemia in adjacent area in 14. Two responses were associated with persistent negative $\mathrm{T}$ waves: an ischaemic response ( 21 of $39(54 \%))$ and persistent akinesis (17 of $39(44 \%))$. The percentage of patients with an ischaemic response who underwent in-hospital elective revascularisation was strikingly higher in patients with delayed restored $\mathrm{T}$ waves than in patients with persistent negative $\mathrm{T}$ waves (39 of $49(80 \%) \quad v 4$ of $21 \quad(19 \%)$, $\mathrm{p}<0.0001$ ) (fig l).

\section{Predictors of $\mathrm{T}$ wave normalisation at hospital discharge}

The 19 patients with early $\mathrm{T}$ wave normalisation were compared with the 108 patients with persistent negative $\mathrm{T}$ waves at hospital discharge. Table 3 shows univariate and multivariate predictors of early $\mathrm{T}$ wave normalisation. Four independent variables distinguishing patients with early $\mathrm{T}$ wave normalisation from those with negative $\mathrm{T}$ waves at hospital discharge were selected stepwise from multivariate logistic analysis: sustained improvement during the dobutamine stress test, mild residual stenosis of the infarct related artery, treatment without elective revascularisation of the culprit lesion, and lower peak concentration of CK-MB.

\section{Predictors of persistent negative T waves}

The 69 patients with delayed $\mathrm{T}$ wave normalisation were compared with the 39 patients with persistent negative $\mathrm{T}$ waves on the four month ECG (table 3). The four independent variables predicting persistent negative $\mathrm{T}$ waves were persistent akinesis during dobutamine stress testing, lack of elective revascularisation, multivessel disease, and lower left ventricular ejection fraction.

\section{Predictors of functional recovery}

At four months' follow up, 48 patients had no functional recovery. Function recovered in 79 of the 127 patients. Table 4 shows a comparison between patients with and patients with no recovery. Patients who recovered had lower peak concentration of CK, had lower in-hospital echocardiographic score index, and more often had Q wave disappearance and $\mathrm{T}$ wave normalisation. Two independent variables distinguishing outcome were selected from multivariate analysis: T wave normalisation $\left(\chi^{2}=9.7, \mathrm{p}=0.0024\right)$ and a lower peak CK concentration $\left(\chi^{2}=4.4, \mathrm{p}=0.039\right)$.

\section{DISCUSSION}

We recorded most variables that can influence the evolution of $\mathrm{T}$ waves in our study patients: estimated infarct size, left ventricular volumes and ejection fraction, the extent and severity of coronary artery disease, wall motion response of the affected myocardium to graded dobutamine infusion, and the presence or absence of functional recovery.

The results of this study support our hypothesis that evolutionary changes of negative $\mathrm{T}$ waves after acute myocardial infarction are determined by both the myocardial state and the treatment strategy. Early restored $\mathrm{T}$ waves are associated with smaller infarct size, mild residual stenosis of the infarct related artery, and contractile reserve without inducible ischaemia. Function is often recovered without revascularisation, indicating that most patients in this category had stunned myocardium. Delayed T wave normalisation between hospital discharge and the four month follow up was observed mainly in patients with viable but

Table 3 Predictors of T wave changes

\begin{tabular}{|c|c|c|c|c|c|c|c|c|}
\hline \multirow[b]{3}{*}{ Data } & \multicolumn{4}{|c|}{$\begin{array}{l}\text { Early } T \text { wave normalisation } v \text { persistent negative } \\
\text { T waves at hospital discharge }\end{array}$} & \multicolumn{4}{|c|}{$\begin{array}{l}\text { Delayed T wave normalisation } v \text { persistent } \\
\text { negative T waves at } 4 \text { months }\end{array}$} \\
\hline & \multicolumn{2}{|c|}{ Univariate } & \multicolumn{2}{|c|}{ Multivariate } & \multicolumn{2}{|c|}{ Univariate } & \multicolumn{2}{|c|}{ Multivariate } \\
\hline & $\chi^{2}$ & p Value & $\chi^{2}$ & $\mathrm{p}$ Value & $\chi^{2}$ & $\mathrm{p}$ Value & $\chi^{2}$ & p Value \\
\hline \multicolumn{9}{|l|}{ Clinical data } \\
\hline Peak CK & 8.4 & 0.0045 & & & & & & \\
\hline Peak CK-MB & 14.8 & 0.0002 & 9.1 & 0.0032 & & & & \\
\hline Anterior infarction & & & & & 8.4 & 0.0038 & & \\
\hline \multicolumn{9}{|l|}{ Echocardiographic data } \\
\hline Baseline score index & 4.2 & 0.04 & & & 7.4 & 0.0076 & & \\
\hline Sustained improvement & 38 & $<0.0001$ & 27.5 & $<0.0001$ & & & & \\
\hline Biphasic response & 11 & 0.0008 & & & & & & \\
\hline Akinesis without change & & & & & 9.9 & 0.0016 & 12.2 & 0.0007 \\
\hline \multicolumn{9}{|l|}{ Angiographic data } \\
\hline LVEF & 6.4 & 0.013 & & & 15.4 & 0.0002 & 4.3 & 0.041 \\
\hline EDV & 7.8 & 0.006 & & & 13 & 0.0005 & & \\
\hline ESV & 7.5 & 0.007 & & & 8 & 0.005 & & \\
\hline$\geqslant 70 \%$ IRA stenosis & 20 & 0.0001 & 20.9 & 0.0001 & & & & \\
\hline Occluded infarct artery & & & & & 7.3 & 0.007 & & \\
\hline$\geqslant 2$ vessel disease & & & & & 8.3 & 0.0039 & 4.5 & 0.037 \\
\hline Revascularisation & 7.9 & 0.0049 & 9.6 & 0.0025 & 10.4 & 0.0013 & 7.4 & 0.008 \\
\hline
\end{tabular}


Table 4 Comparison between patients with and without recovery at four month follow up

\begin{tabular}{|c|c|c|c|c|c|c|}
\hline \multirow[b]{2}{*}{ Data } & \multirow{2}{*}{$\begin{array}{l}\text { No recovery } \\
(n=48)\end{array}$} & \multirow{2}{*}{$\begin{array}{l}\text { Recovery } \\
(n=79)\end{array}$} & \multicolumn{2}{|c|}{ Univariate } & \multicolumn{2}{|c|}{ Multivariate } \\
\hline & & & $\overline{\chi^{2}}$ & p Value & $\chi^{2}$ & p Value \\
\hline Anterior infarction & 23 & 41 & & NS & & NS \\
\hline Thrombolytic treatment & 29 & 59 & & NS & & NS \\
\hline Peak CK (IU/I) & $2184(654)$ & $1721(526)$ & 9.4 & 0.0026 & 4.4 & 0.039 \\
\hline$Q$ wave regression & 4 & 25 & 7.9 & 0.0048 & & NS \\
\hline T wave normalisation & & & 19.9 & 0.0001 & 9.7 & 0.0024 \\
\hline Baseline score index & $1.49(0.28)$ & $1.38(0.26)$ & 5.6 & 0.019 & & NS \\
\hline$\geqslant 2$ vessel disease & 19 & 26 & & NS & & NS \\
\hline Elective angioplasty & 31 & 46 & & NS & & NS \\
\hline
\end{tabular}

jeopardised or hibernating myocardium who during their hospital stay underwent elective angioplasty of the culprit lesion. Persistence of negative $\mathrm{T}$ waves four months after acute myocardial infarction was indicative of either extensive necrosis or jeopardised myocardium that was not revascularised.

\section{$T$ wave evolution and left ventricular function}

Our results confirm the relation between $\mathrm{T}$ wave normalisation and functional recovery after acute myocardial infarction. Few studies have investigated the correlation between ECG changes and left ventricular function. In the GISSI-3 (third Gruppo Italiano per lo Studio della Sopravvivenza nell'Infarto Miocardico) echo substudy, the number of negative $\mathrm{T}$ waves decreased at six months in the majority of patients and this was associated with substantial recovery of regional dysfunction. ${ }^{9}$ T wave normalisation induced by exercise testing predicts myocardial viability ${ }^{8}$ and is often associated with late spontaneous $\mathrm{T}$ wave normalisation on the resting ECG. ${ }^{13}$ In the chronic phase of infarction, patients with restored positive $\mathrm{T}$ waves who benefited from optimal revascularisation of the infarct related artery have better contractile reserve, shown with low dose dobutamine stress echocardiography, than those with negative $\mathrm{T}$ waves. ${ }^{7}$ Few studies have compared patients with early versus delayed $\mathrm{T}$ wave normalisation. Only a recent study has shown that the earlier the negative $\mathrm{T}$ waves reverted to positive, the greater the improvement of left ventricular function, ${ }^{11}$ but the myocardial state was not assessed by any imaging technique. Persistently inverted $\mathrm{T}$ waves were indicative of less recovery, progressive left ventricular enlargement, and decline of global left ventricular function over time. ${ }^{9}$ In a pathology study, persistent negative $\mathrm{T}$ waves $\geqslant 1$ year after acute myocardial infarction were related to the presence of transmural infarction and a fibrotic thin layer. In contrast, positive $\mathrm{T}$ waves were related to nontransmural infarction containing viable myocardium inside the layer. ${ }^{12}$

\section{Mechanisms of $\mathrm{T}$ waves changes}

Regional shortening of monophasic action potentials induces $\mathrm{T}$ wave abnormalities. ${ }^{14} \mathrm{~T}$ wave inversion shortly after ST elevation acute myocardial infarction can be caused by prolonged depression of the action potential characteristics ${ }^{15}$ and denervation supersensitivity of refractoriness. ${ }^{16}$ These early $\mathrm{T}$ wave changes are associated with a high patency rate of the infarct related artery ${ }^{1}$ and salvaged but denervated myocardium. ${ }^{17}$ Spontaneous normalisation of the $\mathrm{T}$ waves is probably related to partial sympathetic reinnervation ${ }^{18}$ or to normalisation of metabolism in viable cells. Restoration of oxidative metabolism is dependent on adequate flow reserve and occurs more rapidly in the absence of severe residual stenosis. In this setting, the acute ischaemic insult results in stunned myocardium, which exhibits sustained contractile improvement during a dobutamine challenge. Stunned myocardium recovers progressively and spontaneously; normalisation of the $\mathrm{T}$ wave is rapid and is usually observed at hospital discharge.

Most patent infarct related arteries, however, have a significant residual stenosis after thrombolysis. ${ }^{19}$ Blunted flow reserve may result in hibernating myocardium, with ultrastructural abnormalities ${ }^{20}$ and a biphasic response to incremental doses of dobutamine. ${ }^{21}$ Timely revascularisation is required in this condition. Given the severity of structural changes of hibernating myocardium, ${ }^{22}$ metabolic and contractile recovery is delayed for several weeks to months. ${ }^{23} \mathrm{~T}$ wave normalisation was not yet present at the time of discharge in our study patients but occurred later and was usually observed on the four month follow up ECG. Some patients may have spontaneously improved perfusion of the affected region resulting from progressive collateral recruitment. Recovery of contraction ${ }^{24}$ and $\mathrm{T}$ wave normalisation ${ }^{11}$ may be even more delayed.

Persistent negative $\mathrm{T}$ waves four months after acute myocardial infarction were associated in our study with two different patterns: jeopardised myocardium not treated by revascularisation; and extensive necrosis. Hibernation is a progressive phenomenon. Absence of revascularisation may lead to apoptosis and development of fibrosis. ${ }^{25}$ Akinesis without change throughout dobutamine stress testing was observed more often in patients with persistent negative $\mathrm{T}$ waves. The absence of any contractile reserve is regarded as a marker of transmural necrosis but can also result from insufficient blood flow or flow reserve despite the presence of viable myocardium. ${ }^{26}{ }^{27}$ Both the severity of left ventricular dysfunction and the unstable condition resulting from hibernation can explain the poor long term prognosis of patients with negative $\mathrm{T}$ waves persisting several months after acute myocardial infarction. ${ }^{56}$

\section{Study limitations}

The results of this study should be considered in the light of several limitations. We did not include patients without early negative $\mathrm{T}$ waves but our purpose was to focus on the determinants of evolutionary changes of negative $\mathrm{T}$ waves. We did not measure left ventricular volumes or regional wall thickness at the four month follow up, which would have permitted better assessment of adverse left ventricular remodelling and transmural extent of necrosis. As the latest ECG was recorded four months after acute myocardial infarction, we could not determine the significance of more delayed T wave normalisation. Similarly, we obtained no ECG between hospital discharge and the four month follow up: the precise time course of normalisation was not identified. The decision to perform revascularisation during hospital stay was made by the physician in charge of the patient: the ECG findings and the results of dobutamine stress echocardiography did not influence the decision. 


\section{Conclusions}

We found that, among patients with negative $\mathrm{T}$ waves recorded beyond 24-36 hours after admission, early versus delayed $\mathrm{T}$ wave normalisation and persistence of negative $\mathrm{T}$ waves have differing determinants. Early normalisation is independently associated with stunned myocardium perfused by a patent artery without severe residual stenosis. A majority of patients with negative $\mathrm{T}$ waves at hospital discharge have viable but jeopardised myocardium. Patients with persistent negative $\mathrm{T}$ waves a few months after acute myocardial infarction should be carefully investigated, including assessment of residual myocardial viability and inducible ischaemia

\section{Authors' affiliations}

L A Pierard, P Lancellotti, Department of Cardiology, University Hospital, Liège, Belgium

\section{REFERENCES}

1 Matetzky S, Barabash Gl, Shahar A, et al. Early T wave inversion after thrombolytic therapy predicts better coronary perfusion: clinical and angiographic study. J Am Coll Cardiol 1994;24:378-83.

2 Kosuge M, Kimura K, Nemoto T, et al. Clinical significance of inverted T waves during the acute phase of myocardial infarction in patients with myocardial reperfusion. J Cardiol 1995;25:69-74.

3 Agetsuma $\mathbf{H}$, Hirai $M$, Hirayama $H$, et al. Transient giant negative $T$ wave in acute anterior myocardial infarction predicts $\mathrm{R}$ wave recovery and preservation of left ventricular function. Heart 1996;75:229-34.

4 Sgarbossa EB, Meyer PM, Pinski SL, et al. Negative T waves shortly after STelevation acute myocardial infarction are a powerful marker for improved survival rate. Am Heart J 2000;140:385-94.

5 The Coronary Drug Project Research Group. The prognostic importance of the electrocardiogram after myocardial infarction: experience in the coronary drug project. Ann Intern Med 1972;77:677-89.

6 Lancellotti P, Gérard PL, Kulbertus HE, et al. Persistent negative T waves in the infarct-related leads as an independent predictor of poor long term prognosis after acute myocardial infarction. Am J Cardiol 2002;90:833-7.

7 Watanabe S, Kawamura Y, Watanabe Y, et al. Viability of Q-wave infarcted myocardium with restored positive and persistent negative $T$ waves after optimal revascularization compared with dobutamine stress echocardiography. Am J Cardiol 2000;85:31-6.

8 Mobilia G, Zanco P, Desideri A, et al. T wave normalization in infarct-related ECG leads during exercise testing for detection of residual viability: comparison with PET. J Am Coll Cardiol 1998;32:75-82.

9 Bosimini E, Giannuzzi P, Temporelli PL, et al. Electrocardiographic evolutionary changes and left ventricular remodeling after acute myocardial infarction: results of the GISSI-3 echo substudy. J Am Coll Cardiol 2000;35:127-35.
10 Tamura A, Nagase K, Mikuriya Y, et al. Significance of spontaneous normalization of negative $T$ waves in infarct-related leads during healing of anterior wall acute myocardial infarction. Am J Cardiol 1999;84:1431-44.

11 Sakata K, Yoshino H, Houshaku H, et al. Myocardial damage and left ventricular dysfunction in patients with and without persistent negative $T$ waves after Q-waves anterior myocardial infarction. Am J Cardiol 2001;87:510-5.

12 Maeda S, Imai T, Kuboki K, et al. Pathologic implications of restored positive T waves and persistent negative T waves after $Q$ wave myocardial infarction. J Am Coll Cardiol 1996;28:1514-8.

13 Pizzetti G, Montorfano M, Belotti G, et al. Exercise-induced T-wave normalization predicts recovery of regional contractile function after anterior myocardial infarction. Eur Heart J 1998; 19:420-8.

14 Autenrieth G, Surawicz B, Kuo CS, et al. Primary T-wave abnormalities caused by uniform and regional shortening of ventricular monophasic action potential in the dog. Circulation 1975;51:668-73.

15 Levine JH, Moore EN, Weismann HF, et al. Prolonged depression of action potential characteristics and a decrease space constant are present in postischaemic reperfused myocardium. J Clin Invest 1987;79:107-10.

16 Kammerling JJ, Green FJ, Watanabe AM, et al. Denervation supersensitivity of refractoriness in noninfarcted areas apical to transmural infarction. Circulation 1987;76:383-93.

17 Inove H, Zipes DP. Time course of denervation of efferent sympathetic and vagal nerves after occlusion of the coronary artery in the canine heart. Circ Res 1988:62:1111-20.

18 Hartikamen J, Kuikka J, Mantysaari M, et al. Sympathetic reinnervation after acute myocardial infarction. Am J Cardiol 1996;77:5-9.

19 Llevadot J, Giugliano RP, McCabe CH, et al. Degree of residual stenosis in the culprit coronary artery after thrombolytic administration (thrombolysis in myocardial infarction (TIMI) trials. Am J Cardiol 2000:85:1409-13.

20 Chen C, Chen L, Fallon JT, et al. Functional and structural alterations with 24hour myocardial hibernation and recovery after reperfusion: a pig model of myocardial hibernation. Circulation 1996;94:507-16.

21 Chen C, Li L, Chen LL, et al. Incremental doses of dobutamine induce a biphasic response in dysfunctional left ventricular regions subtending coronary stenoses. Circulation 1995;92:756-66.

22 Borgers $M$, Thone $F$, Wouters $L$, et al. Structural correlates of regional myocardial dysfunction in patients with critical coronary artery stenosis: chronic hibernation? Cardiovasc Pathol 1993;2:237-45.

23 Cornel JH, Bax JJ, Elhendy A, et al. Biphasic response to dobutamine predicts improvement of global left ventricular function after surgical revascularization in patients with stable coronary artery disease. J Am Coll Cardiol 1998;31:1002-10.

24 Galli M, Marcassa C, Bolli R, et al. Spontaneous delayed recovery of perfusion and contraction after the first 5 weeks after anterior infarction. Evidence for the presence of hibernating myocardium in the infarcted area. Circulation 1994;90:1386-97.

25 Vanoverschelde JL, Melin JA. The pathophysiology of myocardial hibernation: current controversies and future directions. Prog Cardiovasc Dis 2001;43:387-98

26 Lee HH, Davila-Roman V, Ludbrook PA, et al. Dependency of contractile reserve on myocardial blood flow: implications for the assessment of myocardial viability with dobutamine stress echocardiography. Circulation 1997:96:2884-91.

27 Lancellotti P, Albert A, Berthe C, et al. Full recovery of contraction late after acute myocardial infarction: determinants and early predictors. Heart $2001 ; 85: 521-6$.

\section{bmjupdates+}

bmjupdates+ is a unique and free alerting service, designed to keep you up to date with the medical literature that is truly important to your practice.

bmjupdates+ will alert you to important new research and will provide you with the best new evidence concerning important advances in health care, tailored to your medical interests and time demands.

Where does the information come from?

bmjupdates+ applies an expert critical appraisal filter to over 100 top medical journals A panel of over 2000 physicians find the few 'must read' studies for each area of clinical interest

Sign up to receive your tailored email alerts, searching access and more...

www.bmjupdates.com 